\title{
KINETICS STUDY OF WASTE COOKING OIL EPOXIDATION WITH PEROXYACETIC ACID USING ACID CATALYSTS
}

\author{
S. Silviana*, D.D. Anggoro, and A.C. Kumoro \\ ${ }^{1}$ Department of Chemical Engineering, Diponegoro University, Semarang, 50275 Indonesia \\ *E-mail: silviana@che.undip.ac.id
}

\begin{abstract}
Waste conversions into added-value products have been observed in many fields. Bio plasticizers can be prepared with epoxidation of waste cooking oil using glacial acetic acid, hydrogen peroxide, and acid catalysts. Kinetics study of epoxidized waste cooking oil is reported in this paper. The rate constants of the epoxidation using sulfuric acid catalyst were attained about $1.4 \times 10^{-7}, 6.7 \times 10^{-7}, 6.1 \times 10^{-7}, 5.6 \times 10^{-7}, 1.9 \times 10^{-7} \mathrm{~L} / \mathrm{mol} / \mathrm{s}$, and energy activation was obtained at $8.45 \mathrm{kcal} \mathrm{mol}-1$ at range temperature of $40^{\circ} \mathrm{C}$ to $80^{\circ} \mathrm{C}$. The research resulted the most effective catalyst is sulfuric acid followed by hydrochloric acid and nitric acid with the rate constants of $5.6 \times 10^{-7}, 3.9 \times 10^{-7}$ and $2.5 \times$ $10^{-8} \mathrm{~L} / \mathrm{mol} / \mathrm{s}$, respectively. In order to confirm that the epoxidized waste cooking oil was generated by identifying epoxide production and cleavage of epoxide ring, Fourier-transform infrared spectroscopy analysis of the products was conducted.
\end{abstract}

Keywords: Epoxidation, Peroxyacetic acid, Sulfuric acid, Waste cooking oil

(C) RASĀYAN. All rights reserved

\section{INTRODUCTION}

It has been investigated epoxidation of many kinds of vegetable oils converted into plasticizers and polymers ${ }^{1}$. This reaction is well-implemented reaction to obtain the epoxides from unsaturated triglycerides in vegetable oils. Previous researches have resulted in kinetics data such as rate constants of vegetable oil epoxidation, i.e. 0.39-5.4 x $10^{-6} \mathrm{~L} / \mathrm{mol} / \mathrm{s}, 1.4 \times 10^{-6} \mathrm{~L} / \mathrm{mol} / \mathrm{s}$ for cottonseed oil epoxidation ${ }^{1}$ and mahua oil epoxidation, ${ }^{2}$ respectively. Moreover, epoxidized soybean oil have been investigated to plasticize bio-packaging composite ${ }^{3-6}$. It has been compared to the utilization of epoxidized plant oil such as soybean oil and palm oil ${ }^{4}$. It revealed that the epoxidized palm oil releasing composite with highly impermeable to oxygen. This property can be a potential in the packaging of oxygen-sensitive food ${ }^{7}$. Palm oil productivity in 2015 gained 55.70 million tons ${ }^{8}$. Palm oil ensures food security and biofuel feedstock ${ }^{8}$. Applying zero waste for palm oil utility can make the sustainability of the industry ${ }^{8}$. More $80 \%$ of palm oil is used in food chains ${ }^{9}$. Used cooking oil as waste represents an alternative efficient stock for triglycerides ${ }^{10}$. Furthermore, this waste can be utilized such as biosurfactant ${ }^{10}$, biodiesel with base catalyst ${ }^{11}$, biodiesel with a heterogeneous acid catalyst ${ }^{12}$, and also as bioplasticizer due to highly unsaturated triglyceride ${ }^{13}$. There were already investigations of epoxidized WCO by using acid catalysts $^{13}$, and plasticizer of polyvinyl chloride films ${ }^{14}$. Commonly, catalytic epoxidation reaction has been conducted in presence of hydrogen peroxide $\left(\mathrm{H}_{2} \mathrm{O}_{2}\right)$ with many benefits such as releasing only water as side product, contains the largest amount of active oxygen, inexpensive, and less hazardous. ${ }^{15}$ Therefore, this paper uses hydrogen peroxide as the ideal oxidant to release peroxyacetic acid in WCO epoxidation. However, there is no investigation on kinetics study of vegetable oil epoxidation, especially for waste cooking oil epoxidation. The previous result showed the oxirane conversion achieved $20 \%$ by using the catalyst of sulfuric acid in the epoxidation of waste cooking oil ${ }^{13}$. It could expect the demand for reactants and reaction time required to accomplish the reaction based on epoxidation data. Therefore, this paper presents kinetics parameters of WCO epoxidation in peroxyacetic acid using sulfuric acid as a catalyst through the determination of the rate constant. Moreover, functional group identification was

Rasayan J. Chem., 12(3), 1369-1374(2019)

http://dx.doi.org/10.31788/RJC.2019.1235190

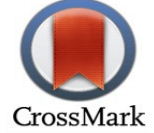


RASĀYAN J. Chem.

Vol. 12 | No. 3 |1369 - 1374| July - September | 2019

undertaken using Fourier-transform infrared spectroscopy (FTIR) to confirm epoxidized WCO and the presence of epoxide ring-opening ${ }^{13}$.

\section{EXPERIMENTAL}

\section{Materials}

Collected WCO was processed to separate solid impurities prior epoxidation reaction. Hydrogen peroxide $/ \mathrm{H}_{2} \mathrm{O}_{2}$ (technical grade) and alcohol (technical grade) were purchased from Brataco Chemical Store in Semarang. Ethanoic acid (pro analysis grade), sodium hydroxide (99\%), potassium iodide $(99,5 \%)$, cyclohexane $(99,5 \%)$, nitric acid (pro analysis grade), chloroiodide solution were purchased from Merck KGaA, Germany without any further treatment. Other chemicals have been prepared under pro analysis grade from Mallinckrodt, such as hydrochloric acid, sulfuric acid, and ethyl ether. Sodium thiosulfate with pro analysis grade was also purchased from Sigma Aldrich.

\section{Methods}

The epoxidation reaction was executed in the laboratory scale by using magnetically stirred flask (500 $\mathrm{mL}$ ) immersed in an oil bath. The flask was provided thermometer controller and water condensor. The following epoxidation method reported in this paper refers to previous research including parameters ${ }^{1,13,16,17}$. At the beginning, double bonding of WCO was analyzed using gas-chromatography mass-spectrometry (GCMS) to determine fatty acids composition ${ }^{13,17}$. Further, the composition of double bonding was used as a parameter of reaction such as acetic acid mole to unsaturated triglyceride mole with a ratio of $0.5: 1$ and $\mathrm{H}_{2} \mathrm{O}_{2}$ to unsaturated triglyceride with a ratio of $2: 1$. Other parameters used were $\mathrm{H}_{2} \mathrm{O}_{2}$ to acetic acid ratio of $2: 1$ and acid catalyst (2\%). The acetic acid and sulfuric acid were poured into the flask. The solution was mixed for a half-hour under stirring speed of $120 \mathrm{rpm}$. The hydrogen peroxide was added dropwise. The end of this addition, the reaction was considered to start for a certain time duration. Prior to analysis, the extraction of free acids was undertaken by using diethyl ether then washed with hot and cold water. Afterward, the samples were analyzed for oxirane oxygen content ${ }^{1}$.

In this paper, the first step is to determine the reaction rate. Thus, the peroxyacetic acid concentration was constantly adjusted within the reaction and regardless of oxirane cleavage due to small dissociation constant for acetic acid ${ }^{5,18}$. The kinetics study follows Eq. $-1^{1}$.

$\left.\left.\frac{d[E P]}{d t}=k / \mathrm{H}_{2} \mathrm{O}_{2}\right]_{0}-[\mathrm{EP}]\right\} \cdot\left[\mathrm{CH}_{3} \mathrm{COOH}\right]_{0}$

Where $[\mathrm{EP}]$ denotes as oxirane oxygen concentration $(\mathrm{mol} / \mathrm{L}), \mathrm{t}$ for time $(\mathrm{s})$, while $[\mathrm{EP}]_{0},\left[\mathrm{CH}_{3} \mathrm{COOH}\right]_{0}$, and $\left[\mathrm{H}_{2} \mathrm{O}_{2}\right]_{0}$ refer to initial concentration of oxirane oxygen $(\mathrm{mol} / \mathrm{L})$, acetic acid $(\mathrm{mol} / \mathrm{L})$, and hydrogen peroxide (mol/L), respectively. The Eq.-2 was determined by integrating the Eq.-1.

$m\left\{\left[\mathrm{H}_{2} \mathrm{O}_{2}\right]_{0}-[\mathrm{EP}]\right\}=-\mathrm{k}\left[\mathrm{H}_{2} \mathrm{O}_{2}\right]_{0}+\mathrm{n}\left[\mathrm{H}_{2} \mathrm{O}_{2}\right]_{0}$

Plotting $\ln \left\{\left[\mathrm{H}_{2} \mathrm{O}_{2}\right]_{0}-[\mathrm{EP}]\right\}$ vs reaction time resulted in many linear lines for the epoxidation reaction neglecting oxirane cleavage ${ }^{1}$.

\section{RESULTS AND DISCUSSION}

Waste cooking oil was analyzed the content of fatty acid confirmed by GCMS. The analysis showed that huge unsaturated fatty acids in triglycerides such as oleic acid around $50 \%$-w based on previous research $^{13}$. The epoxidation experiments were executed with the following variables ${ }^{13}$, such as stirring speed of 1000-1200 rpm, the temperature of 50,60, and $70^{\circ} \mathrm{C}$, the mole ratio of $\mathrm{H}_{2} \mathrm{O}_{2}$ and acetic acid to ethylenic unsaturation of $2: 1$, and $0.5: 1$, respectively. The sulfuric acid catalyst loading was used $2 \%$ of hydrogen peroxide and acetic acid in total weight. Prior to the kinetics study, the preliminary research was conducted to obtain an effective acid catalyst for WCO epoxidation in previous research ${ }^{13}$. The inorganic acid catalyst used were sulfuric acid, nitric acid, and hydrogen chloride. All of these preliminary research temperatures was employed at $60^{\circ} \mathrm{C}$. The relative percentages conversion to oxirane content under three different acid catalysts are visualized in Fig.- $1^{13,19}$. The relative percentages to oxirane content was obtained with the calculation of oxirane oxygen content at the time divided by theoretical oxirane oxygen content. ${ }^{1,13,19}$ Fig. -1 shows that the oxirane conversions using $\mathrm{HCl}$ was lower remarkable than those of $\mathrm{H}_{2} \mathrm{SO}_{4}$ and $\mathrm{HNO}_{3}$ at entire reaction time. Effectiveness of $\mathrm{HCl}$ and $\mathrm{HNO}_{3}$ has not been effectively proven in several epoxidation reactions of vegetable oils ${ }^{1}$. All of the acid catalysts supposed to have sharp rise 
RASĀYAN J. Chem.

Vol. 12 | No. 3 |1369 - 1374| July - September | 2019

towards a maximum, and then downturn with time ${ }^{13}$. However, by $\mathrm{H}_{2} \mathrm{SO}_{4}$, the highest conversion was achieved at around $20 \%$ within 5 hours as long as nearly steep increased ${ }^{13}$. Side reaction denotes as epoxide ring-opening then releasing the downturn of the oxirane conversion ${ }^{13}$. Other research using sulfuric acid as an epoxidation catalyst was reported in other observations ${ }^{1,2}$.

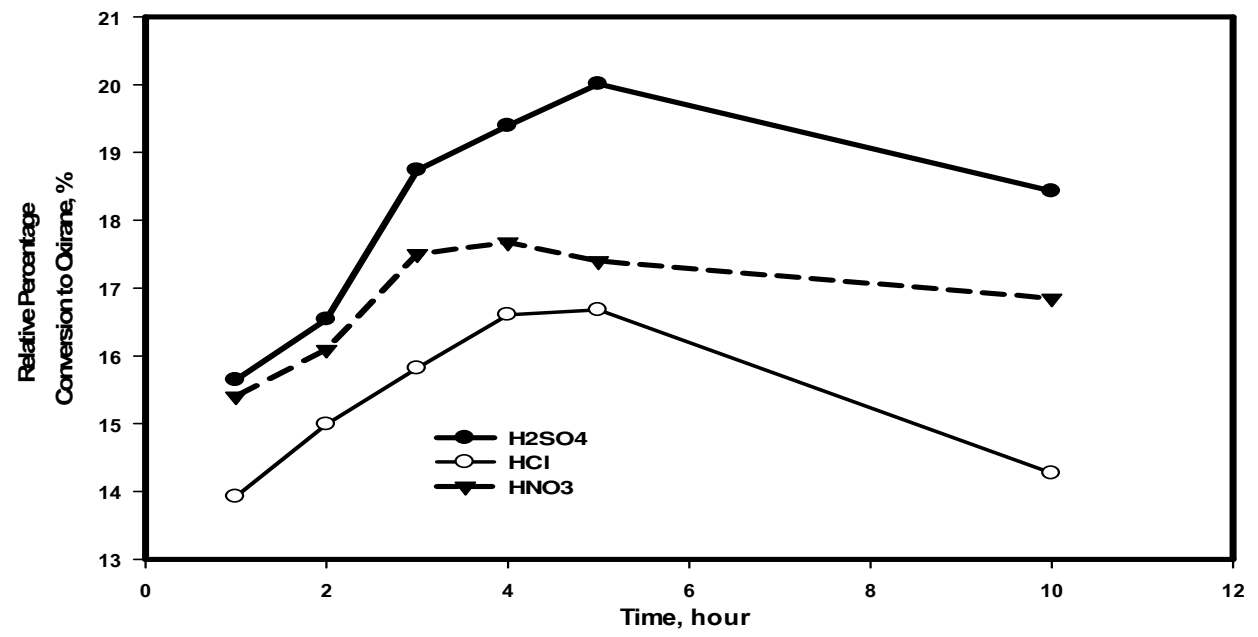

Fig.-1: The Preliminary Research by Relative Percentage Conversions to Oxirane at $60^{\circ} \mathrm{C}$ Under Several Acid Catalysts $^{13}$

The mechanism of epoxidation in the existing of homogenous catalyst is commonly depicted with 2 steps ${ }^{18}$. First, peroxyacetic acid can be formed from reaction of $\mathrm{H}_{2} \mathrm{O}_{2}$ and glacial acetic acid. Second, the product of the first stage can react with unsaturated triglyceride of vegetable oil ${ }^{18}$. The epoxidation reaction involves electrophilic addition mechanism ${ }^{18}$. No remarkable difference in rate constants between $\mathrm{HCl}$ and $\mathrm{H}_{2} \mathrm{SO}_{4}$ as catalyst for WCO epoxidation, while the lowest rate constant was obtained by using $\mathrm{HNO}_{3}$ as catalyst ${ }^{13}$. Moreover, there was almost the same rate constant at a temperature of $50^{\circ} \mathrm{C}$ and $60^{\circ} \mathrm{C}$. However, the increasing temperature at $70^{\circ} \mathrm{C}$ did not increase the conversion to oxirane (EP). It was assumed that the side reaction could open the epoxide ring ${ }^{13}$. Therefore, the number of epoxide content decreased. Natural logarithmic of subtraction of initial $\mathrm{H}_{2} \mathrm{O}_{2}$ mole with oxirane mole can be plotted against time for three acid catalysts at $60^{\circ} \mathrm{C}$ and three different temperatures can be seen in Fig. -2 and Fig.-3, respectively.

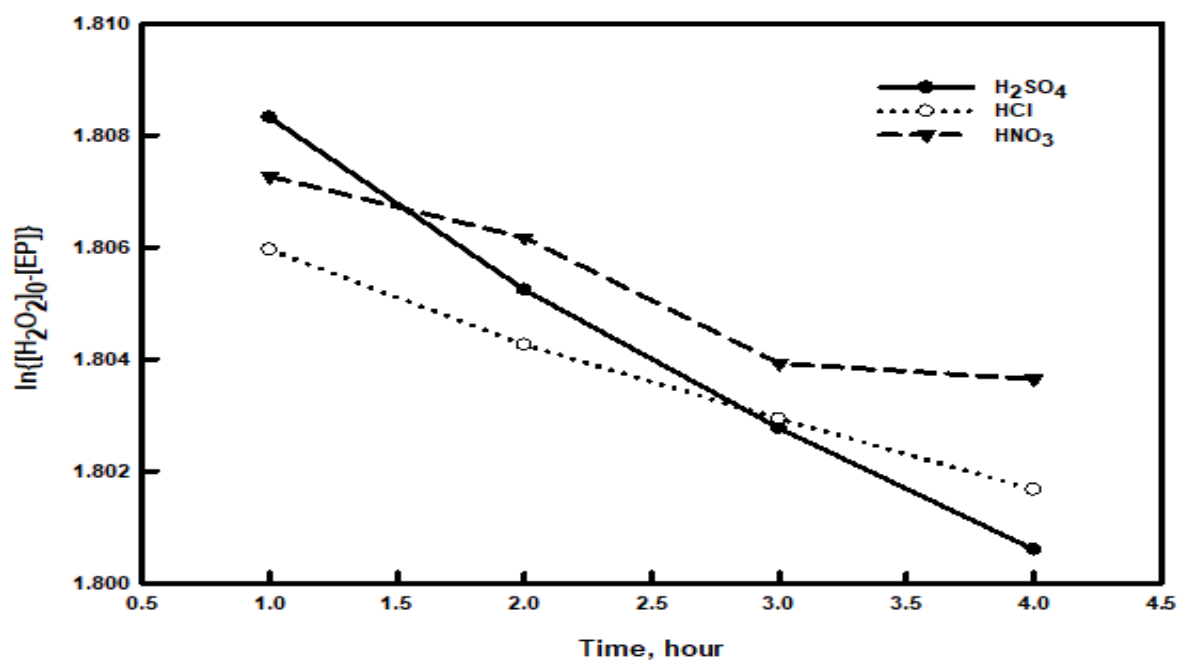

Fig.-2: Plotting $\ln \left\{\left[\mathrm{H}_{2} \mathrm{O}_{2}\right]_{0}-[\mathrm{EP}]\right\}$ vs time of Three Acid Catalysts at $60^{\circ} \mathrm{C}$ for Waste Cooking Oil Epoxidation with Glacial Acetic Acid and Hydrogen Peroxide 
RASĀYAN J. Chem.

Vol. 12 | No. 3 |1369 - 1374| July - September | 2019

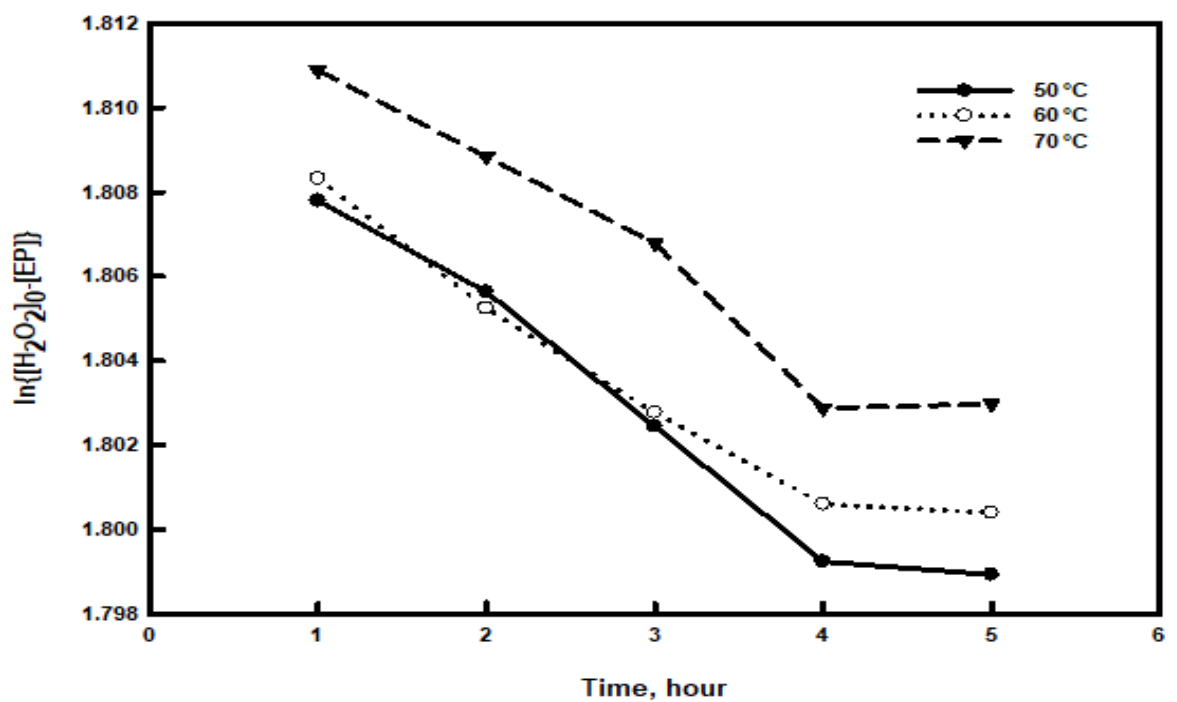

Fig.-3: Plotting $\ln \left\{\left[\mathrm{H}_{2} \mathrm{O}_{2}\right]_{0}-[\mathrm{EP}]\right\}$ vs time of Three Temperatures for Waste Cooking Oil Epoxidation with Glacial Acetic Acid and Hydrogen Peroxide Catalyzed by Sulfuric Acid

The activation energy for the WCO epoxidation using $2 \%$ of sulfuric acid was obtained by calculation of Arrhenius equation slope in Fig.-4. The calculation resulted in approximately $8.45 \mathrm{kcal} / \mathrm{mol}$ of activation energy. This activation energy indicated lower than that of rubber seed oil, methyl ester palm olein, karanja oil, and mahua oil epoxidations, i.e. $15.7^{20}, 15.1^{21}, 14.9^{22}$, and $14.5 \mathrm{kcal} / \mathrm{mol}^{16}$, respectively.

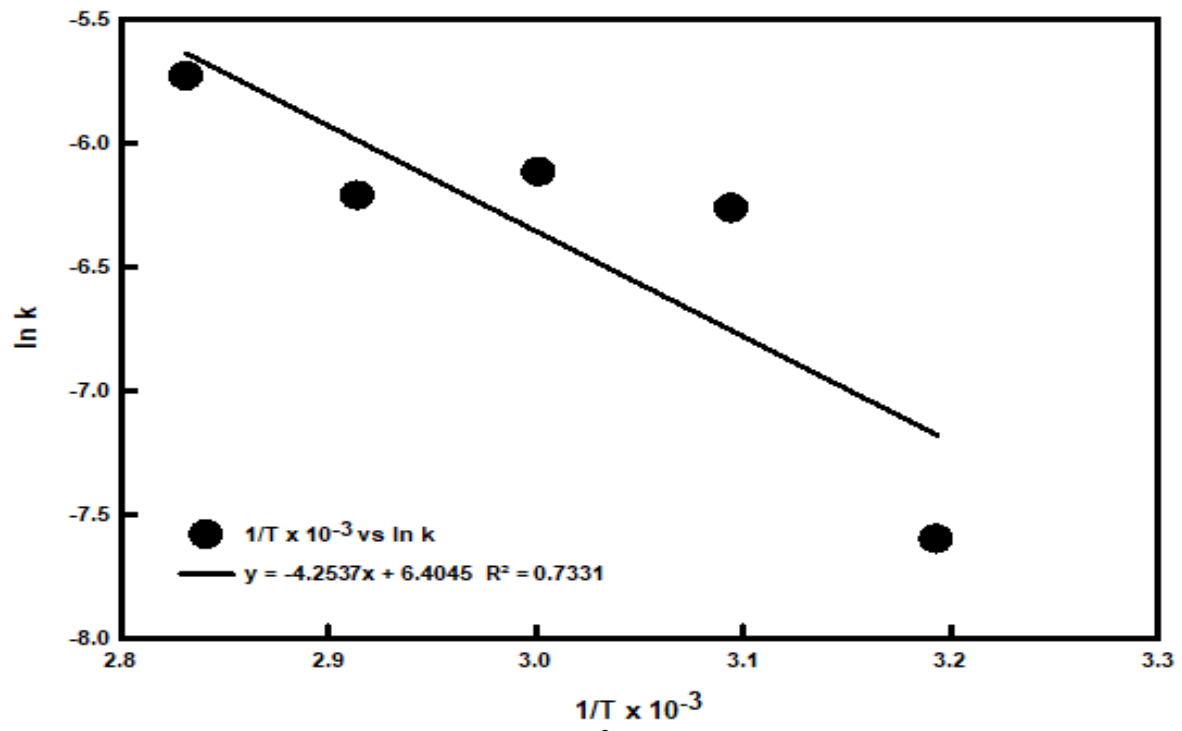

Fig.-4: Plotting of $\ln \mathrm{k}$ vs $1 / \mathrm{T}$ x $10^{-3}$ for Epoxidized Waste Cooking Oil

The presence of acids and water in the reactant might result in oxirane ring-opening ${ }^{18}$. Therefore, it could decrease the epoxidized WCO yield ${ }^{13}$. This result was confirmed by FTIR spectra at previous research in Fig. $-5^{13,17}$. Figure- 5 visualized the spectra of epoxidized $\mathrm{WCO}$ at $70^{\circ} \mathrm{C}$ and $50^{\circ} \mathrm{C}$ catalyzed by $\mathrm{H}_{2} \mathrm{SO}_{4}$, and un-epoxidized waste cooking oil spectra. The epoxidized WCO still stand for the $\mathrm{C}=\mathrm{O}$ ester peak at 1735 $\mathrm{cm}^{-1} 13,17$. Unsaturated triglyceride was referred by vibration mode at $1650 \mathrm{~cm}^{-1}$ and $663 \mathrm{~cm}^{-1}$ at $70^{\circ} \mathrm{C}^{13,17}$. Furthermore, vibration mode at $3410 \mathrm{~cm}^{-1}$ assigned as $\mathrm{C}=\mathrm{O}$ ester was expected as the epoxide ringopening, while the presence of epoxide was indicated by the presence of peaks at $725 \mathrm{~cm}^{-1}$ and $879 \mathrm{~cm}^{-1}$ as regard epoxide ring with single substitution and epoxide ring with vibration in trans mode, respectively ${ }^{23}$. Oxirane compound absorbs infra-red radiation at $750-880 \mathrm{~cm}^{-1}$ and $815-950 \mathrm{~cm}^{-121}$, while 
RASĀYAN J. Chem.

Vol. 12 | No. 3 |1369 - 1374| July - September | 2019

epoxide absorbs around at $1250 \mathrm{~cm}^{-1}$ resulted by $\mathrm{C}-\mathrm{O}$ vibrated stretching and around $370 \mathrm{~cm}^{-1}$ considering ring deformation ${ }^{23}$.

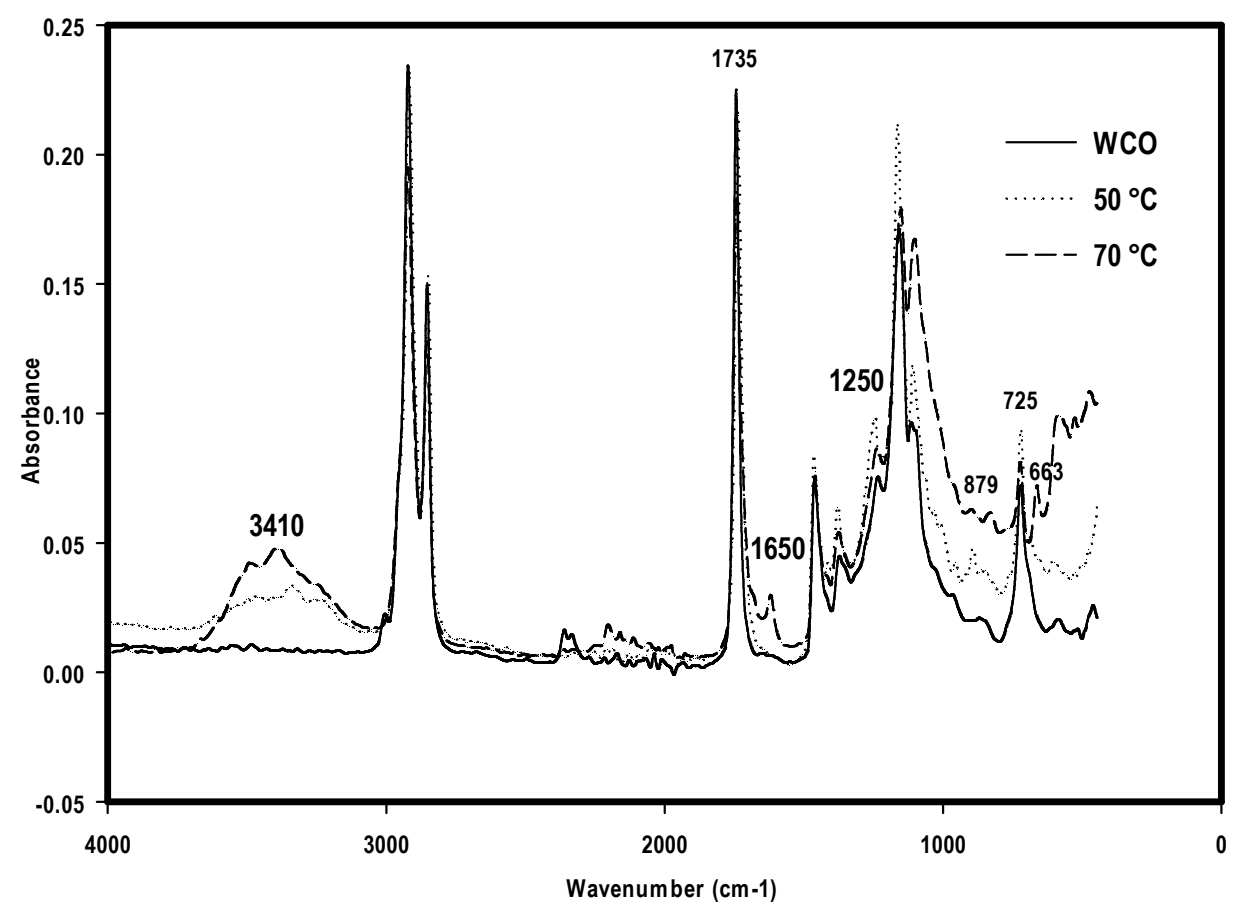

Fig.-5: Functional Group of WCO and Epoxidized WCO at $50^{\circ} \mathrm{C}, 70^{\circ} \mathrm{C}$ by FTIR Analysis ${ }^{13,17}$

\section{CONCLUSION}

1. Kinetics study of WCO epoxidation catalyzed by acids could be effectively and efficiently carried out by sulfuric acid catalyst at a temperature of $60^{\circ} \mathrm{C}$. However, by using $2 \%$ of sulfuric acid with a mole ratio of $\mathrm{H}_{2} \mathrm{O}_{2}$ to unsaturated ethylenic and acetic acid to ethylenic at 2:1 and 0.5:1, respectively was obtained relative percentage conversion to oxirane about $21.69 \%$. Activation energy can be achieved at $8.45 \mathrm{kcal} / \mathrm{mol}$. It was concluded that WCO epoxidation by using $2 \%$ of sulfuric acid released lower the activation energy than that of other plant oils epoxidation.

2. Higher temperature above $50^{\circ} \mathrm{C}$ could downturn the rate constant. Furthermore, it would diminish oxirane conversion, due to opening the epoxide ring at a higher temperature. This evidence was confirmed by the FTIR spectra.

\section{ACKNOWLEDGMENT}

The authors do big appreciate to coworkers at Advanced Material Laboratory, Department of Chemical Engineering of Diponegoro University and also for financial support from university with the grant number (No:276-56/UN7.5.1/PG/2017 on March 23, 2017).

\section{REFERENCES}

1. S. Dinda, A.V. Patwardhan, V.V. Goud and N.C. Pradhan, Bioresources Technology, 99(9), 3737(2008), DOI: 10.1016/j.biortech.2007.07.015

2. V.V. Goud, A.V. Patwardhan and N.C. Pradhan, Industrial \& Engineering Chemistry Research, 46(10), 3078(2007), DOI: $10.1021 / \mathrm{ie} 060146 \mathrm{~s}$

3. C. Bueno-Ferrer, M.C. Garrigós and A. Jiménez, Polymer Degradation and Stability, 95(11), 2207(2010), DOI: 10.1016/j.polymdegradstab.2010.01.027

4. B. Chieng, N.A. Ibrahim, Y.Y. Then and Y.Y. Loo, Molecules, 19(10), 16024(2014), DOI: 10.3390/molecules191016024 
RASĀYAN J. Chem.

Vol. 12 | No. 3 |1369 - 1374| July - September | 2019

5. P. Gogoi, H. Horo, M. Khannam, S.K. Dolui, Industrial Crops and Product, 76, 346(2015), DOI: 10.1016/j.indcrop.2015.06.05

6. M. Rahmah, N.M. Nurazzi, A.R.F. Nordyana and S.M. Syed Anas, Material Science Engineering, IOP Conference Series 223, 012048(2017), DOI: 10.1088/1757-899X/223/1/012048

7. Y.B. Tee, R.A. Thalib, K. Abdan, N.L. Chin, R.K. Basha and K.F. Yunos, Bioresources, 11(1), 1518(2016), DOI: 10.15376/biores.11.1.1518-1540

8. R. Khatun, M.I.H. Reza, M. Moniruzzaman and Z. Yakoob, Renewable and Sustainable Energy Reviews, 76, 608(2017), DOI: 10.1016/j.rser.2017.03.077

9. OECD/Food and Agriculture Organization of the United Nations, OECD-FAO Agricultural Outlook 2015, OECD Publishing, Paris, France (2015), DOI: 10.1787/agr_outlook-2015-en

10. T.D. Wahyuningsih, Y. S. Kurniawan, S. Amalia, T. A. K. Wardhani, and C. E. S. Muriningsih, Rasayan Journal of Chemistry, 12(2), 741(2019), DOI: 10.31788/RJC.2019.1225140

11. M. Saravanakumar, M. Prabhahar, S. Krishnamoorthi, and S. Sendilvelan, Rasayan Journal of Chemistry, 11(1), 372(2018), DOI: 10.7324/RJC.2018.1112024

12. S. Indrayanah, A. Rosyidah, H. Setyawati, and I.K. Murwani, Rasayan Journal of Chemistry, 11(1), 312(2018), DOI: $10.7324 /$ RJC.2018.1111904

13. S. Silviana, D.D. Anggoro and A.C. Kumoro, Chemical Engineering Transactions, 56, 1861 (2017), DOI: $10.3303 /$ CET1756311

14. A.H. Suzuki, B.G. Botelho, L.S. Oliveira and A.S. Franca, European Polymer Journal, 99, 142(2018), DOI: 10.1016/j.eurpolymj.2017.12.014

15. U.S. Agarwalla, Rasayan Journal Chemistry, 11(2), 756 (2018), DOI: 10.31788/RJC.2018.1123029

16. V.V. Goud, A.V. Patwardhan and N.C. Pradhan, Bioresources Technology, 97(12), 1365(2006), DOI: $10.1016 /$ j.biortech.2005.07.004

17. S. Silviana, D.D. Anggoro, Advanced Science Letters 23, 2591(2017), DOI: https://doi.org/10.1166/asl.2017.8726

18. P.K. Gamage, M. O'Brien and L.J. Karunanayake, Journal of the National Science Foundation of Sri Lanka, 37(4), 229(2009), DOI: 10.4038/jnsfsr.v37i4.1469

19. M.H. Shagal, B.A. Barminas, S.A. Aliyu and J. Osemeahon, Journal of Petroleum Technology and Alternative Fuels, 4(4), 72 (2013), DOI: 10.5897/JPTAF2013.0092

20. F.E. Okieimen, O.I. Bakare, and C.O. Okieimen, Industrial Crops and Product, 15(2), 139(2002) DOI: $10.1016 / \mathrm{S} 0926-6690(01) 00104-2$

21. D. Derawi and J. Salimon, E-Journal of Chemistry, 7(4), 1440(2010), DOI: 10.1155/2010/384948

22. V.V. Goud, N.C. Pradhan and A.V. Patwardhan, Journal American Oil Chemistry Society, 83(7), 635(2006), DOI: 10.1007/s11746-006-1250-7

23. G. Socrates, Infrared and Raman characteristic group frequencies, 3rd Ed, John Wiley \& Sons, Michigan, USA, pp 150-200, (2001), published in Journal of Raman Spectroscopy, 35(10), 905(2004), DOI: $10.1002 /$ jrs. 1238

[RJC-5190/2019] 